\title{
The fundamental legal values of modern legal regulation
}

\author{
Viktoria Viktorovna Kovaleva* \\ The North Caucasus Branch of the Federal State Budgetary Educational Institution of Higher Professional Education \\ «Russian State University of Justice», Krasnodar, Russia
}

\begin{abstract}
In modern conditions of the development of society, which is characterized by the exponential development of high technologies that penetrate into all spheres of public life, in a period when the problem of regulating biotechnology, smart cities, all-encompassing digitalization is acute, and all this against the backdrop of the Covid-19 pandemic requires a solution to the issue about fundamental legal values that are necessary for the optimal mediation of social communication in unprecedented circumstances. The aim of the research is to consider the category of "fundamental legal value" and its role in the regulation of legal relations. The object of this research is social relations arising in the process of legal regulation. The subject is fundamental legal values as necessary tools for legal mediation of social communication. The study used dialectical, logical, systemic and structural, functional, formal legal methods. In this study, based on the analysis of modern legal literature, it is concluded that the category "fundamental legal values" is not sufficiently studied and requires further research, while it is necessary to differentiate the value foundations of law and fundamental legal values, where the former are decisive for the latter. The axiological aspect in the study of law is in demand in view of the crisis in the regulation of public relations through law, since in modern conditions of disorientation of society, lockdowns and restrictions, it is necessary to preserve and develop the value orientations of legal regulation, which is possible only through the use of legal instruments, which are fundamental legal values.
\end{abstract}

\section{Introduction}

Modern legal regulation is a dynamic process that changes under the influence of numerous conditions and reasons. Digitalization, the development of high technologies [1], which determine the search, on the one hand, for value foundations, and on the other, for legal instruments for regulating new legal relations, which can also be regarded as values.

As an example, we can cite the transformation of the traditional family, in the scientific literature the same-sex marriage, polygamy and polyamory, alimony, the legal ramifications of cohabitation, gestational surrogacy and assisted reproductive technologies are interpreted [2].

At the same time, the problem should be noted of regulating relations associated with the use of assisted reproductive technologies, which, for example, determines the search for a new necessary legal fixation, for example, the status of an embryo [3]. Thus, modern family relations formulate new requirements for their regulation, raising the question of both the appropriate legal means and their value bases.

In addition, the high-tech world contributed to the emergence of "smart" cities [4], and, accordingly, the need for new legal means of fixing people's communication in a new high-tech environment.

T. Ya. Khabrieva stated that "new social relations are involved in legal regulation that did not exist before, either did not require legal regulation, or objectively could not be regulated by law. The study of the patterns of transformation of the sphere of legal regulation can serve as one of the starting points for the preparation of predictive scenarios for the development of law" [5]. In view of the unprecedented dynamics of modern social relations, this is especially important, since in certain cases it is necessary to work proactively, and try to use the existing legal instruments, combining them in the necessary way and, of course, to use new legal means.

All these processes were strengthened by Covid-19, which has formulated an acute agenda and raises a lot of questions about the optimality of legal regulation, which, of course, is a value in a pandemic. At the same time, Covid-19 forces us to reconsider the role of law, its regulatory potential, limits and opportunities around the world and in each individual country, for example, in China, as noted in one of the scientific publications It revealed that few legal requirements were in fact complied with the fight against the COVID-19 emergency and, Chinese law as such in a time of crisis was indeed in crisis itself [6].

In the legal literature, there are also more emotional statements about the current situation. For example, S.N. Baburin writes that the world familiar to us has plunged into the abyss of digital cross-border chaos by 2021 and needs healing, which can only be provided by its reconstruction on a spiritual and moral basis [7]. In turn, V.M. Artemov notes: "Modern man strives for freedom,

\footnotetext{
*Corresponding author: v.v.kovaleva@list.ru
} 
in many respects even deifies it, but cannot really find it" [8].

It should be noted that both "reconstruction" and return to normal life is possible only with the help of law. As an example, we can cite the attitude of people to distance work in a pandemic, which was and remains different: from complete denial, and vice versa. In such a situation only the state (through law) determined and delimited the multidirectional interests of people. The crisis always intensifies contradictions, and law can reduce their acuteness in the modern world due of its special regulatory properties.

This determines the search for an answer to the question of what values are the basis for the functioning of law, provide its regulatory potential. It is undoubtedly fair to state the fact that the revolutionary development of technologies has such a speed, that society does not have time to realize the degree and breadth of their influence on social relations [9].

We must agree with the assertion that citizens still need legal regulation, but the specificity of the postindustrial society, which manifests itself in an intensively developing state, offers a new vision of the place and role of law, the peculiarities of its perception [10]. In view of this, this study should try to answer three questions. First, how do the concepts of "value of law" and "legal values" relate to each other? Second, what kind of legal values are fundamental. Third, what is the role of fundamental legal values in modern legal regulation.

\section{Results and discussion}

The search for an answer to the above questions necessitates an appeal to the legal heritage of the outstanding Russian scientist S.S. Alekseev, who wrote about the value of law in Soviet society, which has two forms: instrumental (service), where law is a highly effective and expedient social regulator-a tool for other values, and its own value, expressing social freedom, people's activity and social justice [11]. Professor S.S. Alekseev wrote that the understanding that law has its own value is of great ideological, political, scientific and practical significance [11].

For the purposes of this study, we are primarily interested in the instrumental value of law, since legal regulation is a purposeful impact on social relations in order to mediate them by law. Although, of course, both the intrinsic value of the law and the instrumental are in a functional connection, and are conditioned by each other. In turn, under the legal values of S.S. Alekseev meant specific social legal phenomena in which the value of law is expressed, and included among them: human security in conflict situations, certainty and guarantee of law, ensuring the truth in solving legal issues, as well as special legal institutions, legal mechanisms, what is called legal means, technical and legal tools that ensure the value of law [11].

Further, the author, already in the Russian reality of the XXI century, wrote about "fundamental legal values, in which the unique power of law is concentrated", and to them the author attributed the normative and legal structure of social regulation, in particular, the norms of law which, according to S.S. Alekseev represent "models for eternity". The scientist believed that "with their help it is possible and real to create in society, on the basis of experience and reasonable decisions, a reliable, continuously operating consistent system of behavioral models capable (with proper organization and state of the legal system) to determine behavior of people for an indefinitely long time ahead and in any scale covered by this system of relations, and with the possibility of realizing the principles of universality, the principle of balance, equal measure, responsibility" [12].

Further, Professor S.S. Alekseev, along with the normative legal structure, wrote that the defining fundamental value is specific legal ideas and values, as well as legal constructions (in all their diverse varieties) [12], while legal norms are objectified, cast in strict logical forms, legal constructions which are the result of practice, generalization of experience, and in this respect-according to the scientist-the achievement of the mind, the accomplishment of thought [12]. We believe this is the best characteristic of both the rule of law and legal structures.

It should be noted that the dissertation research of M.S. Balayants, who concluded that fundamental are those legal values that are of a systemic nature in the totality of the existing legal values of society due to their generally recognized, obvious, historical and cultural continuity and universality. The author refers to them as freedom, equality, order, justice, public consent in the system [13]. In our opinion, there is a mixture of the value foundations of law, which are mediated by law and become such fundamental legal values as the principles of law, for example, formal equality, justice, humanism, unity of law and obligations, etc. These principles are implemented either directly or, in most cases, through another fundamental legal value, for example, a rule of law, the structure of which, unlike other regulators, includes a sanction, and due to this, not only strictly delimits the multidirectional interests of the parties to the relationship, but also ensures the enforcement of obligations. Moreover, it is legal constructions that are general and specific, such as a legal relationship and a contract, that give certainty to the law as a necessary quality of law [14].

In this context, the point of view from Professor Yu.A. Tikhomirov, according to which: "To ensure the effectiveness of legal regulation, it is necessary to correctly determine the sets of regulators. Incorrectly or hastily created norms, rules do not contribute to stable and consistent regulation and diverse activities in its line. But the matter is not limited to the norms of law, which are traditionally and very statically presented in books on the theory of law and the state. There are more regulators, and these include the principles of law, doctrines and concepts, non-legal regulators acting in a general direction. And this is not enough, since the relationships and dependencies between the regulators remain out of sight" [15]. We should agree with the author about the need for an appropriate choice of legal means, at the same time, I would like to note that, in our 
opinion, non-legal regulators should not be included in the above list, since, we believe, this unjustifiably expands the concept of "legal regulation".

In addition, it should be noted that it is necessary to distinguish between fundamental legal valuesprinciples of law, norms, legal constructions and other legal instruments - that do not have such a fundamental legal nature. In our opinion, these include forms of law that can change, for example, a legal rule can be expressed in a legal custom, which evolves over time and becomes an integral part of the content of a normative legal act; moreover, it can be included in a normative agreement.

Thus, in our opinion, the fundamental legal values are the principles of law, the rule of law, legal structures and the mechanism of legal regulation as a model for regulating future relations, which is necessary for the subjects of law-making activity both in the process of implementing the idea of regulating future relations, and for analyzing how this model "worked" in real conditions, for its subsequent improvement.

It should be emphasized that we differentiate such concepts as "value foundations of law" and "fundamental legal values"- the first is the basis of the secondtherefore, we believe it is necessary to turn to the study of the value foundations of law, which Professor V.S. Stepin called "the invariant core of law" [16].

The issues of the value of law and its functioning are constantly in the center of attention of the scientific community.

An analysis of modern scientific literature has led to the conclusion that in modern conditions there is a search for optimal value foundations for effective regulation of changing and emerging legal relations.

At the present time, a radical rethinking of the value foundations of law is taking place. Thus, one should agree with the point of view of Professor V.S. Stepin, who, as noted in the legal literature, linked the vectors and dynamics of ongoing transformations with a change in basic values and meanings of life, an emerging dialogue of cultures, a change in the technological way of life of society, which, according to Stepin, leads to fundamental changes in law [16]. At the same time, T. Ya. Khabrieva is absolutely right saying that the ideological basis of law is being transformed [16].

Modern researchers refer to the theory of public reason as a right [17]. In this regard, let us cite professor V.N. Kornev who writes: "law, as an object of legal science, is a product of human reason and will, therefore, it is characterized by relative arbitrariness both in the establishment and in its application. Law is formulated, established and applied by people who tend to err. Because of that, law can express and actually expresses the phenomena of consciousness of a deluded human mind and passions that take possession of a person and push him to various abuses, including the establishment of such laws that can be qualified as lawful absence of a right, according to the famous German philosopher of law G. Radbruch. One who thinks otherwise, denies reality" [18].

This statement, of course, makes one question the consideration of reason as the value basis of law. At the same time, we believe, when researchers write about the reasonable grounds of law, they, first of all, mean such "rationality" that expresses the level of freedom, justice and humanism, the combination of which makes law a reasonable regulator of social relations. At the same time, of course, one should agree with V.N. Kornev, that the adopted laws are not always reasonable; this may be a consequence of the legislator's delusion, and may be a purposeful action - there are many cases in history. However, in such cases, we cannot talk about a reasonable basis of law, since it is in such cases that it loses its value. In our opinion, when it comes to law and its value, rationality is always the unity of a certain freedom, justice and humanism. It should be emphasized that the definition of the reasonableness of law does not exist due to the situational (subjective, biased) nature of this concept, as noted by A.G. Karapetov: "subjective concepts that are integrated into the legal system rationality, justice, conscientiousness - are interchangeable. This is playing with words" [19].

In search of an answer to the question of the value foundations of law, we believe it is appropriate to refer to the legacy of G.L.A. Hart, who once wrote: "there are three statements concerning the value of preserving public morality, about which there is a danger of confusion with each other. The first of these statements is the truth, according to which any public morality, no matter what they contain, to a certain extent seeks to realize such universal values as the freedom of the individual, the safety of life and protection from harm. Therefore, in public morality there will always be a lot that deserves to be preserved even at a price expressed in the same values, which presupposes its maintenance with the help of law" [20]. This statement clearly expresses the value of law as a tool for maintaining moral principles. And this is natural, since the emergence of law was due to the lack of moral standards in the delimitation of conflicting interests. It should be noted that the law not only supports, but is also based on universal values. Of course, the value basis of law is justice, being, first of all, a moral category. Justice gives law the necessary regulatory potential that was once discovered when customs and public morality "failed" to exert the required impact on social relations. Justice mediated by law is of particular importance.

Exploring the value foundations of law, one cannot ignore the discussion among lawyers about whether the values underlying law are purely legal or universal, extending not only to legal reality, but also to other spheres of public life [21]. We believe that these values are universal; however, in each sphere - political, economic, social one - they have their own characteristics [22]. For example, justice in economics is, first of all, effective distribution, and for this sphere of relations, law embodies this idea. K. Pistor noted: "Much has been written about the value of law, mostly in ideational terms. In this article, I draw attention to law's pecuniary value. Law, I argue, is the very stuff from which many wealth generating, or capital, assets are made, foremost among them intangible assets that account for most of the private wealth today. For law to serve as a fountain of wealth, it must be backed by state 
power, and indeed, sovereign states have been more than willing to offer a helping hand. They have found intellectual support in neoclassical economics and in its off-spring, law and economics, theoretical approaches that have sought to ground law in the scientific analysis of the economy, in efficiency rather than in justice. In doing so, they have averted their eyes from the fact that the most critical source for wealth, that is law, is itself of the state and should be subject to social norms enshrined in our constitutions, not abstract welfarism" [23].

The problem of the value foundations of law raises the need to pay attention to different interpretations of the value of law in the modern world in the context of their civilizational development, as Y. Kurban writes: norm-value relationship in the context of the "human model" created by the western civilization after industrial revolution and enlightenment, and the meaning given to the human in Islamic civilization. The study also examines the two civilizations in the context of norms based on value patterns [24]. In addition, there is a different perception of the value foundations of law in Russia and in Europe; in particular, S.A. Belov writes: "widely discussed apparent contradictions between traditional Russian Orthodox values and modern secular European values as these contradictions can be observed in the Russian legal system. On the one hand, the 1993 Russian Constitution - in particular, the provisions declaring the highest values of human rights - requires observance of secular European values. On the other hand, the ideas of the 'Russian way' (osobyi put' Rossii) and cultural specificity are very influential in Russian politics and society today" [25].

It should be noted that such value foundations of law as freedom and justice, of course, have different interpretations depending on the peculiarities of historical development, religion and culture of societies. At the same time, when talking about law, we always mean, first of all, a certain freedom and justice, regardless of the factors listed above, which, of course, determine the acuteness of the discussion about the value of law and its regulatory potential.

As V.D. Zorkin: "The task of law is to create such universal mechanisms that, first, would reflect universal human values; secondly, they would offer universal legal methods for resolving social conflicts (the main function of law), independent of purely political or other considerations of expediency; and, thirdly, moving to a different level of generalization would contribute to the preservation of peace and humanity, i.e. general civilization of law" [26]. In our opinion, the very mechanisms that V.D. Zorkin described are fundamental legal values, since legal mechanisms include the norms of law, legal structures of legal relations and legal responsibility, which, when combined, form the necessary algorithm for the operation of law, which is called a mechanism.

\section{Conclusion}

In the reflection on the fundamental legal values defined by outstanding scientists, the question arises whether they retain their significance today, whether they are in the same demand to a greater or lesser extent. We believe that this is especially relevant in connection with the emergence of "smart" regulation.

As noted by M.L. Davydova that "smart regulation": "saves regulatory funds (intervenes only where necessary and as much as necessary); does not rely on its own forces, exercising influence at different levels, involving as surrogate regulators any actors whose participation can ensure the achievement of the goal; does not rely on the mind of the regulator, requiring systematic and systematic interaction of all participants in the regulation in the process of improving the norm; uses a complex of various means, including those that are traditionally not considered to be proper legal; relies on experiment and the need for constant testing of various combinations of regulatory tools in the search for the most effective combination of them; includes all the achievements of other concepts of legal regulation (less regulation, better regulation). But unlike them, the main emphasis shifts from the regulation process to the result, setting the task of achieving this result in the least burdensome way for all participants" [27]. In this context, we believe that no matter how "smart", "best" or whatever the legal regulation is, fundamental legal values as legal means of regulation will remain in demand.

Summarizing, we can draw the following conclusions. The value of law is unconditional; this is demonstrated by the millennium of its existence and the current global crisis. The value of law lies in the fact that by fixing existing moral ideas and principles in the forms of law, it brings the different aspirations of people to a common standard.

Moreover, the pandemic has vividly illustrated the value of positive law, with the help of which states take urgent measures, impose lockdowns and other restrictions, while using fundamental legal values such as principles, rules of law and legal constructions. The whole question is how effectively these fundamental legal values are used, how meaningful they are and how optimally they model existing and emerging legal relations. This question remains open. As rightly, in our opinion, V.D. Zorkin wrote: "Ideal legal models hardly exist. For each historical stage, for each state in different historical periods of their existence, special models of such regulation are needed, fine tuning of the mechanisms of legal regulation is needed. From this point of view, the "right of the future" is an unattainable ideal concept, which, as we approach it, will change and move away again" [26].

Thus, we can formulate three definite answers to the questions posed at the beginning of our study. First, the value of law and fundamental legal values are in a functional relationship. At the same time, it is necessary to differentiate the value foundations of law, as moral requirements for its content, and fundamental legal values, through which these foundations are objectified and acquire their regulatory potential. Secondly, the fundamental legal values as necessary legal means are principles, rules of law and legal constructions. Thirdly, the unprecedented events of the 21 st century, 
determining the crisis in all spheres of public life, cause the demand for fundamental legal values.

\section{References}

1. E. F. Villaronga, A. Jr. Golia, Robots, standards and the law: Rivalries between private standards and public policymaking for robot governance, Computer Law \& Security Review, 35(2), 129-144 (2019)

2. E. Brake, L. Ferguson (eds.), Philosophical Foundations of Children's and Family Law. Philosophical Foundations of Law (Oxford University Press, 2018) 368 p.

3. A.V. Yarosh, Legal status of the embryo as an object of family values, State and Law, 5, 136-143 (2021)

4. B. S. Noveck, Forging Smarter Cities through Crowd, Law Media and Communication, 6(4), 123126 (2018)

5. T.Y. Khabrieva, N.N. Chernogor, The future of law. The Legacy of Academician V.S. Stepin and Legal Sciences (Russian Academy of Sciences; The Institute of Legislation and Comparative Law under the Government of the Russian Federation; INFRAM., Moscow) $176 \mathrm{p}$.

6. Zhiqiong June Wang, Law in crisis: a critical analysis of the role of law in China's fight against COVID-19, Griffith Law Review, 29(2) (2020)

7. S.N. Baburin, Preventing the euthanasia of humanity: morality and integration constitutionalism as the basis for the transformation of modern law, State and Law, 6, 73-86 (2021)

8. A.A. Mokhov, O.V. Sushkova (eds.), Genetic Technologies and Law During the Formation of Bioeconomics: Monograph (Prospekt, Moscow, 2020) 632 p.

9. E.E. Nikitina, The system of human rights and freedoms in the context of the technological revolution, Journal of Russian law, 8, 27-44 (2020)

10. M.A. Belyev, V.V. Denisenko, A.I. Klimenko (eds.), Legal Order: Introduction to the General Theory: Monograph (Prospekt, Moscow, 2020) 208 p.

11. S.S. Alekseev, Problems of the theory of state and law: Textbook (Jurid. lit., Moscow, 1987) 448 p.

12. S.S. Alekseev, Mystery and power of law. Science of law: new approaches and ideas. Right in the life and fate of people (Norma, Moscow, 2009)
13. M.S. Balayants, Fundamental legal values of modern society: abstract of candidate dissertation (Moscow, 2007) 25 p.

14. V.V. Ershov, Regulation of legal relations (RGUP, Moscow, 2020) $568 \mathrm{p}$.

15. Yu.A. Tikhomirov, Legal regulation: theory and practice (Formula Prava, Moscow, 2008) 400 p.

16. T.Y. Khabrieva, N.N. Chernogor, The future of law. The Legacy of Academician V.S. Stepin and Legal Sciences (Russian Academy of Sciences; The Institute of Legislation and Comparative Law under the Government of the Russian Federation; INFRAM., Moscow) $176 \mathrm{p}$.

17. G. Ballingrud, Public Reason as Highest Law, Law and Philos, 37, 145-170 (2018)

18. V.N. Kornev, Theory of state and law as a legal science, State and Law, 7, 7-21 (2021)

19. Retrieved from: https://pravo.ru/lf/story/211503/?lf_mob_news 54=

20. G.L.A. Hart, Law, freedom and morality (Publishing house of the Gaidar Institute, Moscow, 2020). 136 p.

21. A.V. Kornev (Ed.), Problems of history, methodology and theory of legal science: monograph (Norma, INFRA-M, Moscow, 2018) p. 350 .

22. V.A. Vaypan, A Theory of Justice: Law and Economic: monograph (Yustitsinform, Moscow, 2017) $280 \mathrm{p}$.

23. K. Pistor, The value of law, Theor. Soc., 49, 165186 (2020). DOI: https://doi.org/10.1007/s11186$\underline{020-09388-\mathrm{Z}}$

24. Y. Kurban, Norm-Value Relationship in Islamic and Western Law, Journal of History Culture and Art Research, 7(5) (2018). DOI: https://doi.org/10.7596/taksad.v7i5.1794

25. S.A. Belov, Conflicting Russian Orthodox and European Secular Values and Their Reflection in Russian Law, Review of Central and East European Law, 41(3-4), 219-262 (2016). doi: https://doi.org/10.1163/15730352-04103002

26. V.D. Zorkin, Providentia or the law of the future in the era of digitalization, State and Law, 6, 7-19 (2020)

27. M.L. Davydova, "Smart regulation" as the basis for improving modern lawmaking, Journal of Russian law, $\quad 11, \quad 14-29 \quad$ (2020) 